\title{
Dynamic behavior of the horizontal milling and drilling machine spindle assembly with Dynrot software
}

\author{
Nicoleta Luminiţa Căruțașu ${ }^{1 *}$, Nicoleta Elisabeta Pascu $^{2}$, George Căruțașu ${ }^{3}$ \\ ${ }^{1}$ University Politehnica of Bucharest, nicoletacarutasu@yahoo.com, Romania \\ ${ }^{2}$ University Politehnica of Bucharest, nicoletaelisabeta pascu@yahoo.ro, Romania \\ ${ }^{3}$ Romanian-American University, carutasu.george@profesor.rau.ro, Romania
}

\begin{abstract}
This article presents research conducted to study the dynamic behavior of the assembly of a horizontal milling CNC machine spindle at the speed of $10000 \mathrm{rpm}$ and 50000 rpm. This step aims to determine the critical rotation speeds of the complex system "spindle bearings", by drawing Campbell diagrams. The rotor is a subset of these machines, consisting of a shaft, in which the one or more discs, and which executes a rotating motion around the axis propyl. The curve Campbell contours in the diagram represents the variation of natural pulsations of spindle system, depending on the speed bearing spindle.
\end{abstract}

\section{Introduction}

About high speed processing machines cutting, quality of a product is based on the fulfillment of all customer requirements, presented by A. Dugas, J.-J. Lee, and J.-Y. Hascoët in [1]. For this reason, it is necessary to use all the knowledge about quality assurance since the time of the study phase/design, detailed by E. B. Msaddek, Z. Bouaziz, M. Baili, and G. Dessein [2]. Very high spindle speeds are needed to achieve cutting speeds, that can been predicted using dedicated software, G. Patrascu and G. Carutasu in [3]. High advance speeds can be achieved

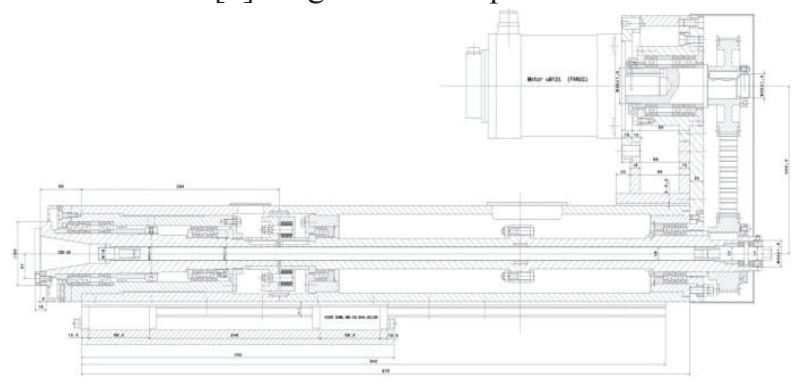

Fig. 1. The main kinematics chain of horizontal milling and drilling CNC machine. Numerical simulation of dynamic response of spindle assembly at the rotation speed of 10000 RPM

Numerical simulation of dynamic response of spindle system (first section) - bearings, rotation speed of 10000 only with the appropriate essential transmissions and stable structure of the machine tool with good vibration damping, shortcuts are necessary for implementing high cutting speed range, expressed by K. Jauhari, A. Widodo, and I. Haryanto in [4]. Although the variety of machines rotors (as types and sizes) is great even within the same sub-class machines, however, they have a common element: the rotor, concluded by V. Gagnol, B. C. Bouzgarrou, P. Ray, and C. Barra in [5].

The study case is made for a milling and drilling $\mathrm{CNC}$ machine. In this case, the rotor is equated with the machine tool spindle and gears, elements running around propyl rotation axes are treated as discs that are assembled on the spindle (Fig. 1). rpm, is based on all use DYNROT program [6]. Similar studies driven by K. Jauhari, A. Widodo, and I. Haryanto [7], C. E. H. Ventura and A. Hassui [8] and H. Cao, T. Holkup, and Y. Altintas [9] were made combining Finite Element Method (FEM) method using ANSYS, in case of static behavior and ANSYS Parametric Design Language (APDL) for dynamic behavior. Also, for the presented horizontal milling and drilling machine spindle, presented by N. L. Carutasu [10] the static behavior analyses using FEM method and ANSYS software.

We have achieved, in a first step, the spindle meshing with beam elements four degrees of freedom for each node, of those eight degrees of freedom for each element to obtain the same number of elements. Fig. 2 presents

\footnotetext{
Corresponding author: nicoletacarutasu@yahoo.com
} 
sketch highlighting the main spindle nodes have been placed elastic elements. In this case, the placement of them has been taken into consideration, and the manner of mounting of the bearings: the "O" or "X".

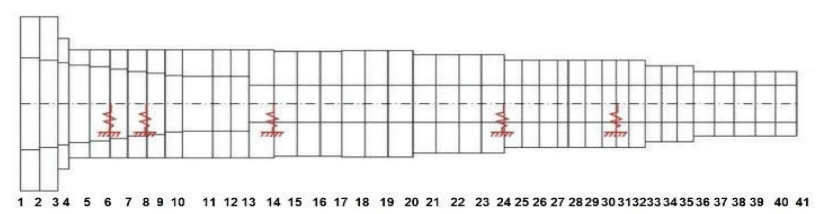

Fig. 2. Sketch of the mine spindle

The graphical representations contain both the deformed shape of the mine shaft and ellipses precession motion of the shaft center of each section. Along with graphical representations are offered information on shaft speed expressed in rpm and natural frequency value expressed in $\mathrm{Hz}$.

Due to the relatively high rigidity of bearings, natural frequencies and critical rotation speeds that are relatively high (the lowest value is approx. $16207 \mathrm{rpm}$, presented in Table 1) resulting from this that the mine shaft will not achieve a critical rotation speed when idle. The graphical space representations of the first eight own modes precession is presented in Fig. 5.

Table 1. Values of first eight natural frequency for $10000 \mathrm{rpm}$

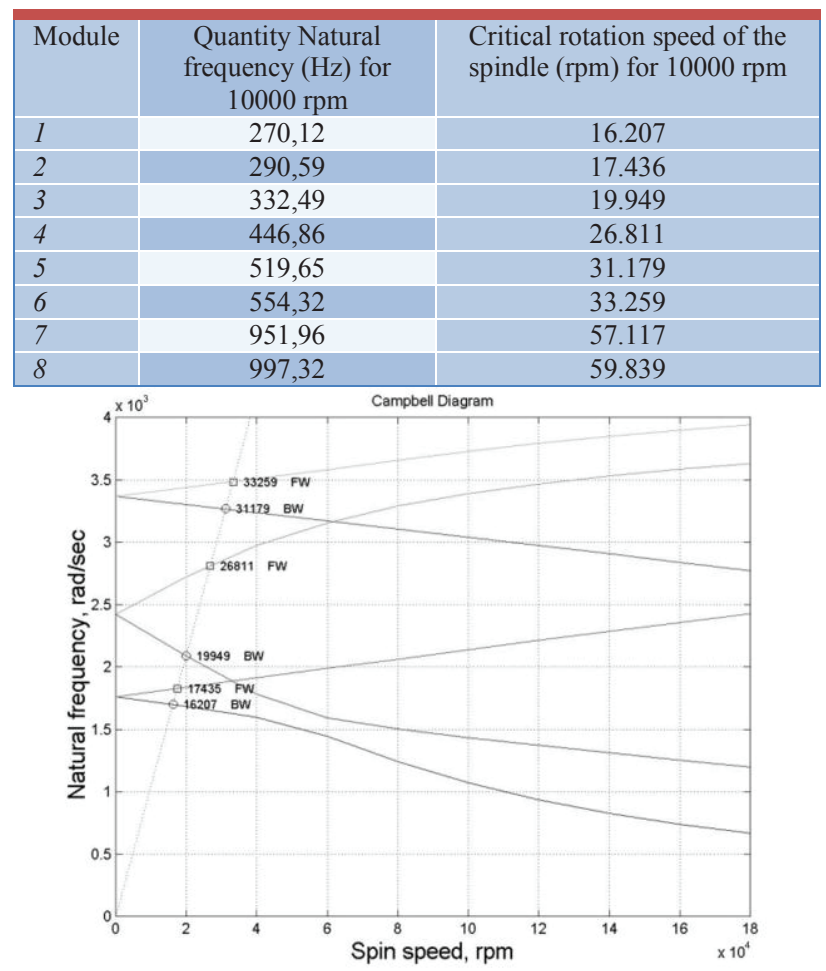

Fig. 3. Campbell diagram, for $10000 \mathrm{rpm}$

Backward whirl (BW) represents deformed shaft rotates around the axis in the opposite bearings than the sense that rotates around its axis shaft and Foreword whirl (FW) it is deformed shaft rotates around the axle bearings in the same sense that also rotates on its own axis.

\section{Numerical simulation of dynamic response of spindle assembly at the rotation speed of 50000 RPM}

Using the computer program DYNROT, it performed a numerical simulation of the dynamic response of 50000 rpm to determine critical rotation speeds of the system by drawing Campbell diagram (Fig. 4). The graphical space representations of the first four own modes precession is presented in Fig. 6.

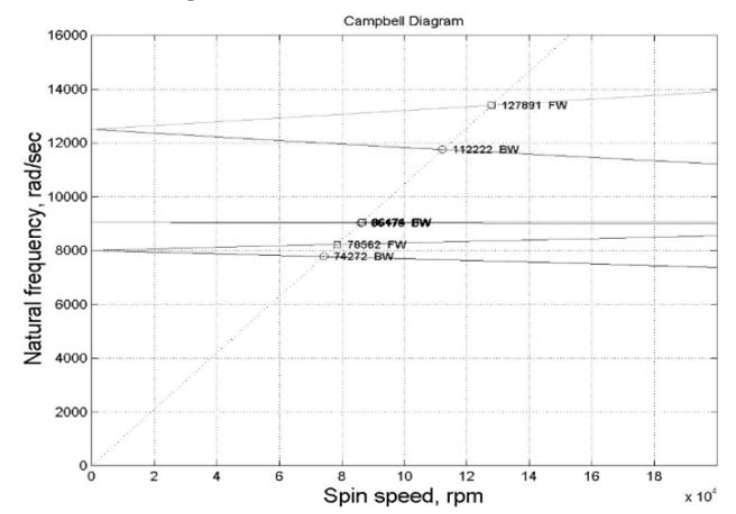

Fig. 4. Campbell diagram, for $50000 \mathrm{rpm}$

Table 2. Values first six natural frequency for $50000 \mathrm{rpm}$

\begin{tabular}{|l|c|c|}
\hline Module & $\begin{array}{c}\text { Quantity Natural } \\
\text { frequency }(\mathrm{Hz}) \text { for } \\
50000 \mathrm{rpm}\end{array}$ & $\begin{array}{c}\text { Critical rotation speed of the } \\
\text { spindle (rpm) for 50000 rpm }\end{array}$ \\
\hline 1 & 1237,40 & 74272 \\
\hline 2 & 1308,90 & 78532 \\
\hline 3 & 1436,30 & 86175 \\
\hline 4 & 1441,30 & 86477 \\
\hline 5 & 1870,50 & 112222 \\
\hline 6 & 2131,50 & 127891 \\
\hline
\end{tabular}



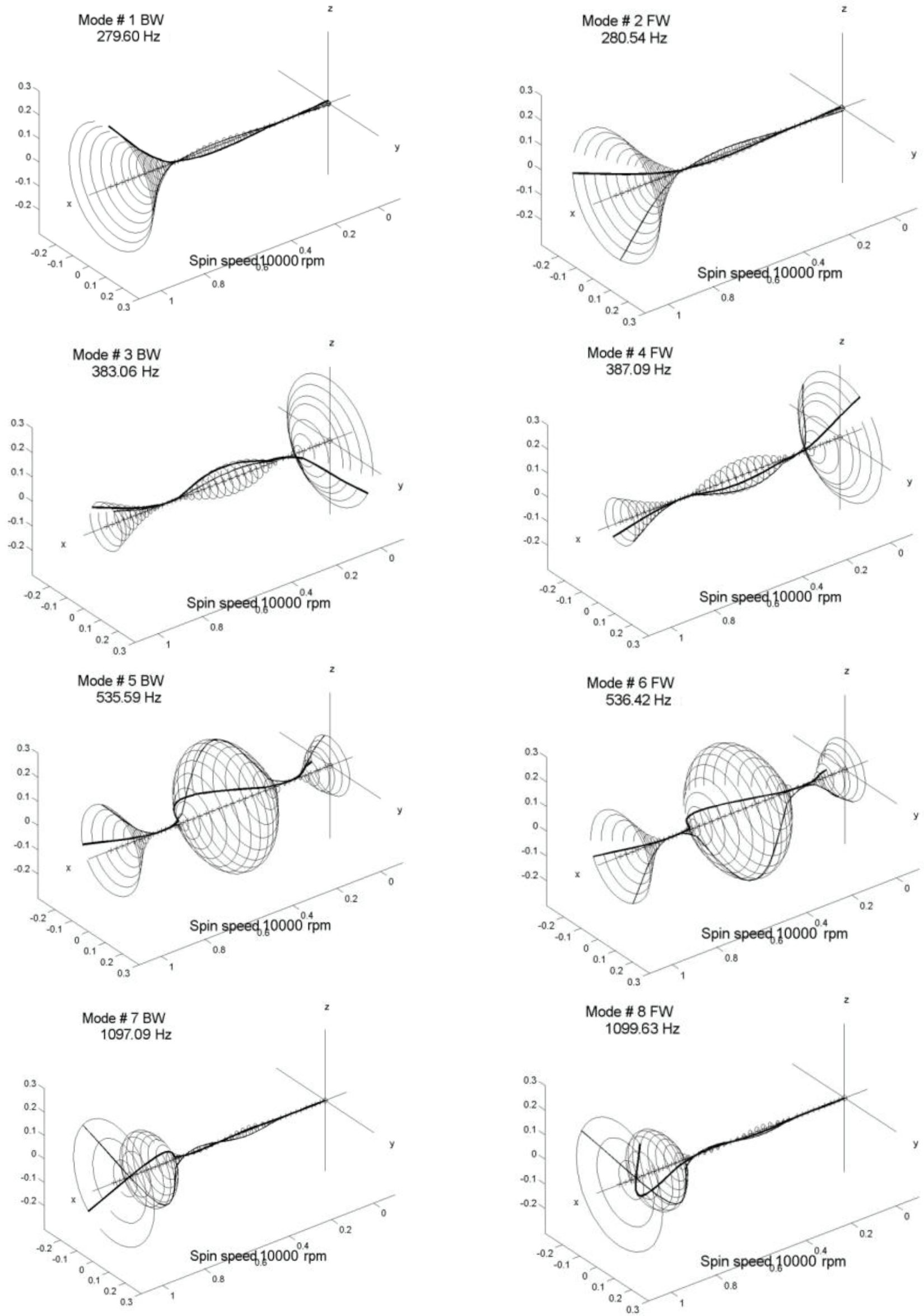

Fig. 5 Graphical space representations of deflection shape 

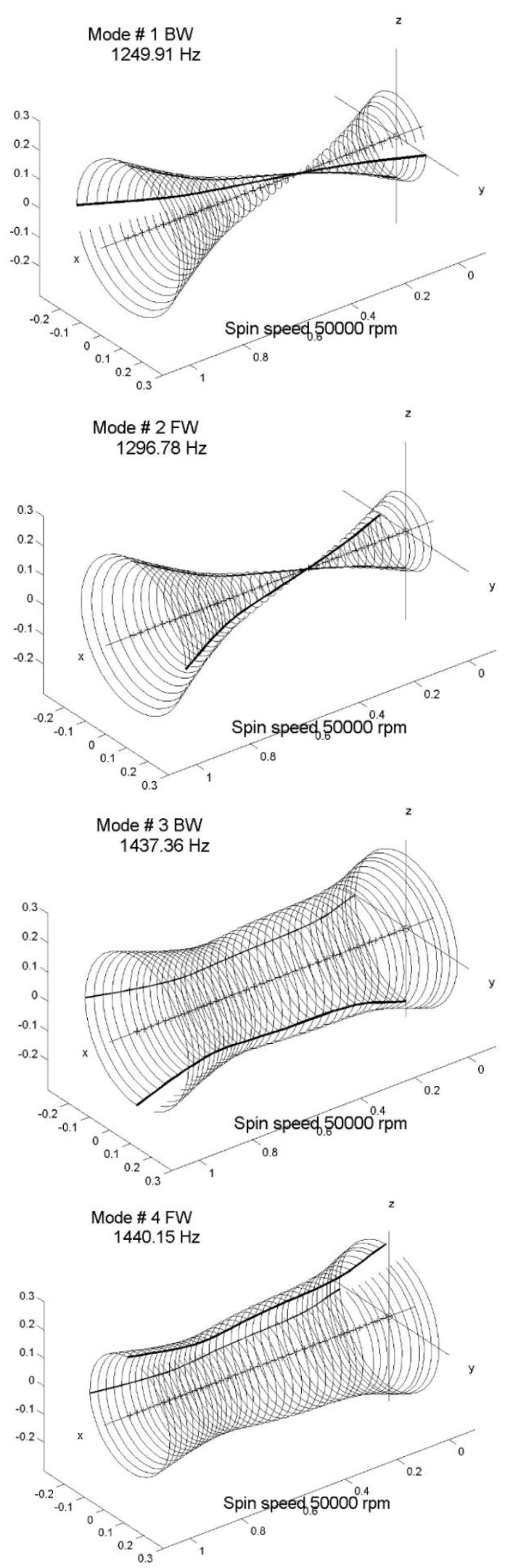

Fig. 6 Graphical space representations of deflection shape corresponding to own the precession modes for $50000 \mathrm{rpm}$.

\section{Conclusions}

Comparing numerical simulations of the dynamic response of spindle assembly at $10000 \mathrm{rpm}$ and 50000 rpm rotation speeds, can be seen that the natural frequency decrease with backward whirl (BW) with increasing spindle speed and increase with foreword whirl (FW). Also, precession own modes are pairs (FW and $\mathrm{BW}$ ) which is observed in the form of precession own modes and differ as form. Natural frequencies and critical rotation speeds that are high in case with 50000 rpm rotation speed (the lowest value is approx. 74242 rpm), self-excited vibrations may occur but when certain conditions are met related to the cutting process, but they should not be confused with critical rotation speeds of the mine spindle. Campbell diagrams are different; the variation curves traced its pulsations spindle - bearings system on the main shaft rotation speed (Fig. 3 and 4). The occurrence of resonance and hence a critical rotation speeds occurs when the own pulsation (in $\mathrm{rad} / \mathrm{sec}$, or natural frequency expressed in $\mathrm{Hz}$ ), is equal to the corresponding shaft rotation speed (Campbell diagrams appear that marked these intersections and values critical rotation speed). In conclusion, it can say that in terms of reuse system, it can be used in machine tools with an extended working a speed of the mine spindle structure is stable in terms of dynamic response.

\section{References}

[1] A. Dugas, J.-J. Lee, and J.-Y. Hascoët, "High Speed Milling," in Integrated Design and Manufacturing in Mechanical Engineering, Dordrecht: Springer Netherlands, 2002, pp. 287294.

[2] E. B. Msaddek, Z. Bouaziz, M. Baili, and G. Dessein, "Modeling and simulation of high-speed milling centers dynamics," Int. J. Adv. Manuf. Technol., vol. 53, no. 9-12, pp. 877-888, Apr. 2011.

[3] G. Patrascu and G. Carutasu, "Using virtual manufacturing simulation in 3D cutting forces prediction," Ann. ORADEA Univ., vol. 5, pp. 1423-1426, 2007.

[4] K. Jauhari, A. Widodo, and I. Haryanto, "Evaluation of Dynamic Behavior a Machine Tool Spindle System through Modal and Unbalance Response Analysis," World Acad. Sci. Eng. Technol. Int. J. Mech. Aerospace, Ind. Mechatron. Manuf. Eng., vol. 9, no. 2, pp. 400-406, 2015.

[5] V. Gagnol, B. C. Bouzgarrou, P. Ray, and C. Barra, "Dynamic Analyses and Design Optimization of High-Speed SpindleBearing System," in Advances in Integrated Design and Manufacturing in Mechanical Engineering II, Dordrecht: Springer Netherlands, 2007, pp. 505-518.

[6] Sobriety, "DYNROT User Manual." 2016.

[7] K. Jauhari, A. Widodo, and I. Haryanto, "Identification of a Machine Tool Spindle Critical Frequency through Modal and Imbalance Response Analysis," Am. J. Eng. Appl. Sci., vol. 9, no. 2, pp. 213-221, 2016.

[8] C. E. H. Ventura and A. Hassui, "Evaluation of static cutting forces and tool wear in HSM process applied to pocket milling," Int. J. Adv. Manuf. Technol., vol. 65, no. 9-12, pp. 1681-1689, Apr. 2013.

[9] H. Cao, T. Holkup, and Y. Altintas, "A comparative study on the dynamics of high speed spindles with respect to different preload mechanisms," Int. J. Adv. Manuf. Technol., vol. 57, no. 9-12, pp. 871-883, Dec. 2011.

[10] N. L. Carutasu, "Virtual simulation for static behavior of the main spindle assembly of a horizontal drilling and milling CNC machining with a high-speed cutting," Ann. ORADEA Univ. Fascicle Manag. Technol. Eng., no. 2, pp. 125-128, 2016.

\footnotetext{
*Corresponding author: nicoletacarutasu@yahoo.com
} 